\title{
O que é, afinal, conhecimento cumulativo?
}

What is cumulative knowledge after all?

Resumo: Depois dos anos 6o, e especialmente depois da repercussão da obra kunhiana, tornou-se comum a distinção entre o ponto de vista continuísta e o descontinuísta na avaliação do desenvolvimento científico. Kuhn passou a ser visto como o grande descontinuísta ao lado de Koyré e Butterfield e foi considerado o causador de uma grande mudança no modo de se conceber o desenvolvimento da ciência. Em diversas abordagens, a noção de continuidade tem sido, muito frequentemente, equiparada à acumulação, que implica necessariamente a negação da existência de revoluções científicas. Neste trabalho, buscamos mostrar que o emprego dos adjetivos "cumulativista" ou "continuísta" em oposição ao termo "descontinuísta” pode tanto suscitar interpretações equivocadas de visões históricas quanto estabelecer aproximações entre visões bastante distintas. Isso parece claro quando se analisa, por exemplo, as concepções de Sarton, Conant e Kuhn sobre a acumulação, tarefa a que nos propomos. A análise propicia considerações sobre os papeis desses pensadores na história da ciência.

Palavras-chave: acumulação, continuidade, Sarton, Conant, Kuhn.

Abstract: After the 6o's, and especially after the repercussion of kuhn's work, it became trivial to distinguish between a continuist and a discontinuist point of view in relation to the scientific progress. Kuhn came to be seen as the great discontinuist, along with Koyré and Butterfield, and he was the one considered responsible for a major change in the way of conceiving the development of science. In several approaches the notion of continuity has been usually equivalent to the notion of cumulativeness, which necessarily implies the assumption of the absence of revolutions in science. This paper tries to show that the use of the "cumulativist" or "continuist" epithets as opposed to "discontinuous" can both evoke misinterpretations of historical views and establish approximations between very different views. This seems clear when ones analyzes, e.g., Sarton, Conant and Kuhn's views about cumulativeness, the task this paper proposes to do. The analysis provides considerations on the roles of these thinkers in the history of science.

Key-words: cumulativeness, continuity, Sarton, Conant, Kuhn.

\footnotetext{
${ }^{1}$ Professora do Departamento de Filosofia da Faculdade João Paulo II. E-mail: amelijeso@gmail.com. Trabalho realizado com financiamento da Fundação de Amparo à Pesquisa do Estado de São Paulo - FAPESP/ Processo 2013/20172-0.
} 
Em A estrutura das Revoluções científicas, Kuhn manifesta suas expectativas de contribuição para a história do desenvolvimento científico e, valendo-se da análise do trabalho de outros historiadores, propõe uma abordagem inovadora quanto ao modo de se conceber a própria ciência. Nesse sentido, apesar de mencionar os eventos comumente já designados de revoluções - as relacionadas aos nomes de Copérnico, Newton, Lavoisier e Einstein (Cf. KUHN, 197ob, p. 6) -, sua análise implica em novo conceito de revolução ${ }^{2}$.

Ao mencionar positivamente o trabalho de historiadores que vinham desenvolvendo "novos tipos de questões e a traçar linhas diferentes e frequentemente cada vez menos cumulativas de desenvolvimento para as ciências" (KUHN, 197ob, p. 3), Kuhn estabelece uma distinção entre uma historiografia mais tradicional e uma nova historiografia da ciência que sugeria a possibilidade de uma "nova imagem de ciência”. Suas ideias, desde então, se tornaram uma referência para a discussão sobre o desenvolvimento científico e, de modo geral, foram consideradas como prevalecentes em comparação à historiografia mais antiga.

Para muitos de seus intérpretes, Kuhn teria promovido uma ruptura com a historiografia continuísta. ${ }^{3} \mathrm{E}$, em muitos casos, a noção de continuidade aparece atrelada à de cumulatividade, no sentido de ausência de mudanças revolucionárias. No entanto, a identificação de adeptos da visão histórica combatida por Kuhn nem sempre tem se mostrado clara ou isenta de ressalvas. Na maioria das vezes, a oposição entre desenvolvimento contínuo e/ou cumulativo versus conhecimento descontínuo é abordada de modo rápido e já estabelecida. Isso ocorre na literatura historiográfica de seus intérpretes e não propriamente nos textos kuhnianos.

A "revolução historiográfica”, após Kuhn, implicou, tal como ele identificou na análise de uma revolução científica, uma mudança conceitual. Se ele introduziu novos termos à análise filosófica e histórica da ciência, tais como "paradigma”, “crise” e incomensurabilidade, é também verdade que alterou significados que já estavam disponíveis,

\footnotetext{
${ }^{2}$ Ver Oliveira (2014).

${ }^{3}$ Ver, por exemplo, Alfonso-Goldfarb e Beltran (2004, p. 53). Beltrán (1995, p. 167) opõe “continuísmo" a "rupturismo", sendo Kuhn inserido no segundo movimento.
} 
como "revolução" e "conhecimento cumulativo". Quando investigamos essas noções em outros pensadores, podemos verificar uma singularidade que dificulta ou põe em cheque certas confluências ou antagonismos entre visões que são corriqueiros na literatura de seus intérpretes. Nosso propósito neste artigo é investigar a noção de conhecimento cumulativo nas visões de Sarton e Conant, com vistas na mudança historiográfica identificada por Kuhn. Ao fazê-lo, buscamos mostrar que a junção desses pensadores sob uma mesma denominação ("cumulativistas" ou "continuístas") e a oposição entre cumulativismo e descontinuísmo ou rupturismo podem mais obscurecer do que iluminar a análise da mudança historiográfica.

No que segue, apresentamos inicialmente o esboço de um quadro comum estabelecido para se distinguir os dois modos de se avaliar o desenvolvimento científico que, em última análise, pode gerar malentendidos na interpretação dos pensadores envolvidos nessa discussão. A seguir, focamos nossa análise na noção de conhecimento cumulativo nas visões de Sarton e Conant. Mais do que assinalar notáveis diferenças entre elas, nosso intuito é mostrar que, de modos distintos, ambas desempenharam um papel significativo para o desenvolvimento da história da ciência, fato que, como veremos na seção seguinte, direta ou indiretamente, os escritos de Kuhn evidenciam.

\section{Algumas interpretações das visões de Sarton, Conant e Kuhn sobre o desenvolvimento científico}

É comum a interpretação de que o conceito de revolução científica passou a ganhar relevo por volta dos anos $50^{4}$. Bernard Cohen, em seu livro Revolution in Science, publicado em 1985, identifica a obra de Butterfield, The Origins of Modern Science (1949) e a de Rupert Hall, The Scientific Revolution 1500-180o (1954), como estudos proeminentes nessa análise. Contudo, a seu ver, a aceitação geral do conceito de revolução como "um fenômeno que ocorre regularmente" na ciência ocorreu "somente depois da publicação do livro de Kuhn" (BERNARD COHEN, 1994, p. 389). Com A estrutura das revoluções científicas, Kuhn teria "alterado radicalmente nossa visão sobre a mudança científica", afirma

${ }^{4}$ Ver, por exemplo, Béltran (1995, p. 27). 
Bernard Cohen (1994, p. 22, 23), que explica que a concepção antes dominante era a de mudança cumulativa, como a defendida por Sarton:

George Sarton, um dos primeiros fundadores da disciplina acadêmica de história da ciência, não foi um grande adepto da crença em revoluções científicas. Ele chegou até a afirmar que é somente nossa "primeira impressão do progresso científico", superficial, que nos mostra a ciência avançando por passos gigantes descontínuos, como um conjunto "gigantesco de escadas, com cada enorme degrau representando uma daquelas descobertas essenciais que levaram a humanidade, quase repentinamente, a se elevar a um nível mais elevado". Quando "empreendemos nossa análise", ele diz, encontramos "os grandes degraus... dividindo-se em menores, e estes em outros ainda menores, até os degraus desaparecerem completamente" [...] Muitos cientistas concordaram [...] A análise de Sarton o levou a conceber que o aspecto essencial da ciência era seu caráter cumulativo; [...] a única atividade humana "verdadeiramente cumulativa e progressiva" - um julgamento com o qual J. B. Conant $(1947,20)$ e outros concordaram (BERNARD COHEN, 1994, p. 22). 5

Quando se refere ao modelo cumulativo ou "incremental” Bernard Cohen (1994, p. 389) justapõe o nome de Sarton ao de Conant, que é mencionado em sua obra sobre revoluções científicas somente como exemplo de adepto da visão cumulativa. Isso também ocorre em seu texto "Revolution, Evolution and Emergence" (1987), no qual estabelece uma oposição entre revolução e evolução. Mach e Duhem aparecem aí como representantes de uma linhagem cumulativista que, mais tarde, comportaria Sarton e Conant, em oposição à visão que propaga a ocorrência de revoluções na ciência, como a de Koyré, Butterfield, Hall e, sobretudo, Kuhn.

Outro intérprete que discute o antagonismo de Kuhn frente à visão cumulativa e que associa essa visão a Sarton e Conant é John Preston, quando afirma:

Kuhn associa cumulativismo a uma tradição epistemológica ou "paradigma" que tem dominado a filosofia ocidental desde a revolução científica $[\ldots]$

\footnotetext{
5 Pinto de Oliveira (2012, p. 10) lembra a equiparação feita por Cohen entre Sarton e Conant acerca da visão de progresso cumulativo, quando discute a diferença de perspectiva histórica entre Sarton e Kuhn.
} 
Os positivistas e empiristas lógicos podem estar abertos para objeção de que sua imagem de ciência era formada não pela atenção à ciência real e sua história, mas por trabalhar sob a presunção a priori de que cientistas devem usar métodos que fazem sentido quando apresentados em lógica formal. Mas o cumulativismo não surge somente da abordagem 'lógica' da ciência, como oposta à histórica.

A história cumulativista tem sido escrita [...] também por historiadores e filósofos profissionais da ciência, incluindo figuras como Willian Whewell, Émile Meyerson, o mentor de Kuhn, James Bryant Conant, e George Sarton (PRESTON, 2008, p. 53).

Preston admite a existência de diferenças entre os cumulativistas e comenta a visão de William Whewell como exemplo de um "historiador cumulativista sofisticado" (PRESTON, 2008, p. 54), que partilhou pontos de vista importantes sobre a ciência com Kuhn. Ainda que tenha a clara intenção de mostrar a complexidade envolvida na abordagem do cumulativismo frente ao descontinuísmo, Preston faz lembrar a associação entre cumulatividade e continuidade, presente na historiografia da ciência que, muitas vezes, conjuga a visão de Sarton a outros pensadores, como, por exemplo, Duhem ${ }^{6}$ :

[...] há uma tradição inteira de filósofos e historiadores da ciência [...] que não somente fornecem uma alternativa ao revolucionismo de Kuhn, mas que a elaboram sobre uma fonte (teoria da evolução), à qual, como nós temos visto, Kuhn conectou sua própria obra.

Kuhn trata Whewell, Mach e Duhem como representantes de uma tradição filosófica singular e decisiva na historiografia da ciência (ET, pp. 106-107). Mas a sua acusação de que os cumulativistas não consideram a história da ciência falha seriamente em registrar a extensão interpretativa disponível ao fazer história da ciência. Nem continuidade nem revolução está escrita na face da ciência e supor de outra maneira é falhar em levar em consideração o fato (do qual Kuhn estava bem consciente em outro

\footnotetext{
${ }^{6}$ A associação entre cumulatividade e continuidade do progresso científico está presente em Agassi (1973, p. 6o9). Note-se como a definição de Agassi está próxima daquela apresentada por Bernard Cohen, citada acima, quando se refere a Sarton: "A teoria da continuidade afirma idealmente que a mudança histórica procede gradualmente por pequenos passos e nega, assim, a existência de quaisquer mudanças ou revoluções repentinas e em grande escala”. Alfonso-Goldfarb e Beltran (2004, p. 50) afirmam que Sarton seguiu e perpetuou "um modelo baseado nas tendências epistemológicas da virada do século, contemplando ideias de estudiosos como E. Mach e P. Duhem e pressupondo o desenvolvimento contínuo e acumulativo da ciência”. Lombardi (1997, p. 345-346) cita Duhem e Sarton como exemplos de historiadores representantes da "tese da continuidade cumulativa do conhecimento científico" que está estreitamente relacionada à historiografia Whig e em oposição à historiografia antiwhig de Kuhn. Beltrán (1995, p. 3-5; 34-35) estabelece vínculo entre as "teses continuístas" de Duhem e Sarton. Ver Oliveira (2012).
} 
lugar) de que a história é uma disciplina interpretativa (e, portanto, parcialmente filosófica) (PRESTON, 2008, p. 54).

A análise de Preston sobre as distintas visões do desenvolvimento científico, como se pode observar, apresenta a posição kuhniana frente a visões de diversos pensadores. E evidentemente, importa, nessas circunstâncias, a caracterização de conhecimento cumulativo. E aí ele circunscreve a crítica kuhniana a uma "versão particular de cumulativismo", que seria bem sucedida:

A versão em questão, que Kuhn encontra no início do positivismo lógico, e que ele associa com as visões "instrumentalistas" de teorias, certamente parece restritiva. Ela afirma, grosso modo, que novas teorias não se destinam para superar velhas teorias, mas meramente para limitar seu domínio de aplicação (PRESTON, 2008, p. 54-55).

Contudo, se a crítica kuhniana parece restrita a uma versão "particular" de cumulativismo, por que e para que relacioná-la a outras caracterizações cumulativistas? E ainda: a partir de quais pressupostos, detectáveis na obra kuhniana, tem ocorrido a classificação de filósofos e historiadores como continuístas e/ou cumulativistas? Certamente essa análise pode ser realizada, mas o que encontramos normalmente é uma correlação já pronta, elaborada a partir de repetições de passagens extraídas das obras de estudiosos que afirmam que o desenvolvimento da ciência se processa de modo contínuo ou cumulativo, sem uma análise do que esses estudiosos compreendem pelos adjetivos que empregam. Daí que cabe indagar: "contínuo" e "cumulativo" têm o mesmo significado em diferentes usuários destes termos? Vejamos o caso de Sarton.

\section{O conhecimento cumulativo em George Sarton}

A afirmação de que a ciência se desenvolve cumulativamente é encontrada facilmente nas obras de Sarton ${ }^{7}$, mas nenhuma aparece tão comumente nos escritos de seus intérpretes como a publicada em The Study of the History of Science, em 1936, que é a que segue:

\footnotetext{
${ }^{7}$ Ver, por exemplo, Sarton (1988, p. 10; 1962a, p.1; 1962b, p. 55).
} 
828 | Veritas | Porto Alegre, v. 63, n. 3, set.-dez. 2018, p. 822-855

Definição. A ciência é conhecimento positivo sistematizado ou o que tem sido tomado como tal em diferentes épocas e lugares.

Teorema. A aquisição e a sistematização do conhecimento positivo são as únicas atividades humanas que são verdadeiramente cumulativas e progressivas.

Corolário. A história da ciência é a única história que pode ilustrar o progresso da humanidade. De fato, o progresso não tem significado definitivo e inquestionável em outros campos como no campo da ciência (SARTON, 1957 [1936], p. 5).

A “definição" e o "teorema” de Sarton são úteis para ilustrar a compreensão da perspectiva de seu autor. Mas, como qualquer outra afirmação que sintetize uma visão, se tomada isoladamente, pode gerar interpretações não necessariamente fiéis. Analisemos a definição acima. Quando Sarton usa a expressão "ou o que tem sido tomado como tal em diferentes épocas e lugares” possibilita a interpretação de que "conhecimento positivo sistematizado" pode ter sofrido alterações ao longo do tempo e ter sido interpretado de modo distinto (e mesmo assim ter sido considerado ciência). Outras passagens de seu texto, tomadas isoladamente podem suscitar a mesma interpretação - a do caráter cambiante da noção de ciência. Assim, por exemplo, ele afirma: "a descoberta da radioatividade, a introdução dos quanta e as teorias da relatividade têm obrigado todo físico e químico a mudar radicalmente seus modos de pensar sobre coisas essenciais [...] A ciência não é um ser, mas um tornar-se" (SARTON, 1927, p. 25). Em outro texto lemos: “O conhecimento não é algo morto e estático, mas algo fluido, vivo e em movimento" (SARTON, 1957, p. 5). Outras passagens extraídas e isoladas da obra de Sarton podem dar a impressão de uma atitude compreensiva do historiador frente ao contexto histórico investigado. Tome-se, como exemplos, as seguintes afirmações: "Todo homem de ciência foi um homem de seu tempo e lugar, de sua família e povo, de seu grupo e igreja” (SARTON, 1959a, p. xiii). "Leonardo [da Vinci] fez tudo o que ele poderia fazer em seu tempo" (SARTON, 1953, p.14). Essas passagens isoladas, no entanto, como veremos a seguir, não dominam a perspectiva histórica sartoniana.

Voltamos à definição de Sarton: a que corresponde, então, a noção de "conhecimento positivo"? A caracterização do conhecimento científico empreendida no capítulo introdutório de sua principal obra, The 
Introduction of The History of Science $^{8}$, tem um desdobramento esclarecedor de sua visão histórica acerca do empreendimento científico, quando ele discute a ciência da Idade Média. Sarton afirma aí:

\begin{abstract}
Apesar das crises políticas e das tendências obscurantistas, o conhecimento positivo deve aumentar e se acumular. Todo progresso nessa direção, por menor que seja, foi decisivo e irrevogável. Assim, nós podemos dizer que cura do escolasticismo foi simplesmente o progresso do conhecimento positivo e isso significa o progresso do método experimental (SARTON, p. 1927, p. 24, grifos nossos).
\end{abstract}

Embora Sarton (1927, p. 15) revele que tivesse alterado sua visão da Idade Média, vista anteriormente como um período de regressão, a análise que apresenta da ciência realizada no medievo é ainda bastante depreciativa, quando ele assinala a mudança que ocorreu com o advento da ciência moderna - essa, sim, boa representante do conhecimento positivo sistematizado. No capítulo introdutório de sua mais importante obra, ele repete que "a cura do escolasticismo era a ciência experimental" e que o progresso da ciência deve ser concebido como "uma luta contínua entre o empirismo e o dogmatismo, entre a interpretação criativa de fatos novos e a tentativa de comprimi-los numa estrutura aceita [...] entre o espírito experimental e o escolástico" (SARTON, 1927, p. 25).

Na concepção sartoniana, o verdadeiro espírito da ciência consiste na "contínua alternância da pesquisa experimental, da elaboração matemática (se possível), da dedução teórica e discussão sugerindo novos experimentos" (SARTON, 1927, p. 24). O progresso do conhecimento científico é cumulativo porque sempre soma novas verdades e é sistematizado porque pressupõe uma organização, uma unificação que coordena o conhecimento já existente e as novas hipóteses, que suscitam métodos para investigar o ainda desconhecido. A ciência é "essencialmente um sistema, mas, ao invés de ser um sistema fechado, como era para os escolásticos, nunca é fechado, mas sempre sujeito à revisão ou até mesmo ao completo descarte" (SARTON, 1927, p. 24, 25).

\footnotetext{
${ }^{8}$ A obra, publicada em cinco partes, compõe três volumes publicados entre 1927 e 1948 e foi idealizada como uma introdução para a história da ciência desde os tempos pré-históricos até o século XX. Sarton, no entanto, a interrompeu quando estudava a ciência do século XIV. Perspectivas do grande projeto são encontradas em Sarton (1921); relatos das motivações da interrupção do projeto, em Sarton (1962a, 367-368; 1975, p. 5-7).
} 
Por essas características, a ciência se distingue das outras atividades humanas, conforme a expressão de Sarton no teorema citado acima, que diz que a "aquisição e a sistematização do conhecimento positivo são as únicas atividades humanas que são verdadeiramente cumulativas e progressivas”. Sarton (1927, p. 3-4) compara o desenvolvimento da ciência ao da arte e da religião. A seu ver não é possível afirmar que os santos de seu tempo eram mais santos que os de antigamente; que os artistas contemporâneos haviam se tornado melhores do que os da Grécia, nem tampouco que os cientistas se mostravam mais inteligentes que seus predecessores. No entanto, é certo que o conhecimento científico havia se tornado "mais extensivo e acurado". Em outro texto, Sarton (1988 [1931], p. 11) faz o mesmo tipo de consideração e indaga: "Se Ésquilo e Sófocles assistissem a nossas modernas obras teatrais, o que pensariam delas? O que diriam de nossas exposições de arte?” Sua conjectura é de que considerariam essas criações artísticas como uma verdadeira performance ou como uma piada. Tudo porque, em sua visão, não há progresso na arte, terreno em que a criação é muito mais arbitrária do que na ciência.

Sarton (1957, p. 51, n.1) lembra a consideração de Einstein ${ }^{9}$, que teria afirmado "que o cálculo infinitesimal certamente teria sido descoberto mesmo se não tivesse existido nenhum Newton e nenhum Leibniz", mas que "sem Beethoven, nunca teríamos tido uma sinfonia em C menor". Apesar de admitir a possibilidade de que o desenvolvimento da sinfonia poderia ter continuado depois de Mozart (o que corrobora a arbitrariedade da criação artística), Sarton afirma que permanece verdadeira a individualidade do trabalho de Beethoven e assim como seu caráter insubstituível, enquanto que o de Newton "teria sido, mais cedo ou mais tarde, substituído por algo equivalente”. Enquanto a criação de Beethoven era casual, a de Newton era certa e necessária, o que remete à afirmação de Sarton no corolário mencionado acima, a de que "a história da ciência é a única história que pode ilustrar o progresso da humanidade. De fato, o progresso não tem significado definitivo e inquestionável em outros campos como no campo da ciência”"10.

\footnotetext{
${ }^{9}$ Vale lembrar que Einstein é mais um nome lembrado por Bernard Cohen (1987, p. 203) entre os defensores do modelo incremental ou cumulativo para o desenvolvimento da ciência.

${ }^{10}$ Sobre a diferença entre o desenvolvimento da arte e o da ciência, ver ainda Sarton (1948, p. 24-26).
} 
"O principal postulado da ciência é a unidade da natureza", diz Sarton (1927, p. 30). E essa unidade é confirmada, de modo indireto, pelo desenvolvimento de todo o conhecimento. A seu ver, só existe progresso porque o universo possui regularidades e cada descoberta científica é uma confirmação desse postulado. A história da ciência estabelece essa unidade pelos menos de dois modos: primeiro, pela interdependência do progresso entre as ciências, já que nenhuma delas é independente das demais; juntas, formam um todo orgânico ${ }^{11}$. O segundo modo é pela existência de descobertas simultâneas, que provam que, quando diferentes homens de diferentes nações chegam a um mesmo resultado, existe uma harmonia interna na natureza. A ciência pode ser comparada, diz Sarton (1927, p. 31) "a uma cadeia de fatos que estão ligados em uma ordem invariável". Desse modo, o historiador não deve estar interessado somente nas mais novas conquistas da ciência, mas em toda sua evolução, uma vez que

[o]s últimos resultados são como os novos frutos de uma árvore. Eles servem para nossas necessidades imediatas. Contudo, sem a árvore, eles não poderiam nascer. $\mathrm{O}$ historiador da ciência deseja conhecer a árvore do conhecimento com todas suas raízes e ramificações. Ele aprecia os frutos de hoje, mas não mais do que aqueles do passado e do futuro (SARTON, 1962a, p. 6-7) ${ }^{12}$.

A justificação em prol do valor da história da ciência reside no fato de que ela é o centro da história da cultura. Ao conhecer o passado científico, diz Sarton, (1930, p. xvii) podemos nos conscientizar da história da humanidade, que é "essencialmente a história de uma gigantesca luta entre a luz e a escuridão, entre o conhecimento e a ignorância”. A história da ciência é a história das descobertas e invenções, com aplicação da razão na investigação da natureza. Neste sentido, ela é, em grande medida, a história do racionalismo (Cf. SARTON, 1959b, p. x). O historiador, entretanto, quando investiga essa história, percebe que a busca pela verdade não ocorreu sem uma luta contra erros e superstições. Essa perspectiva sartoniana está expressa em suas considerações sobre a

\footnotetext{
${ }^{11}$ Sobre as inter-relações entre as ciências no que diz respeito ao progresso, ver ainda Sarton (1962a, p. 10-11).

${ }^{12}$ Observação semelhante é encontrada em Sarton (1957, p. 5). A necessidade do historiador conhecer todo o passado da ciência para se analisar as conquistas mais recentes está manifesta na própria obra de Sarton. The Introduction of The History of Science foi concebida pela necessidade de conhecer os antecedentes de Leonardo da Vinci, quando ele planejou compor "Uma enciclopédia Leonardesca". Ver Sarton (1919; 1962a, p. 367- 368) e Stimson (1962, p. IX).
} 
ciência da Idade Média, conforme vimos acima, quando ele se refere à escolástica. Seus textos sobre Leonardo da Vinci também revelam a identificação da luta entre a razão e a superstição, com manifestações lastimosas por Leonardo não ter realizado plenamente a ciência moderna, já que foi incapaz de se emancipar completamente de preconceitos platônicos e galênicos ${ }^{13}$ e por este motivo, não efetivou a descoberta da circulação do sangue, realizada mais tarde por Harvey ${ }^{14}$. Ao mesmo tempo em que procura identificar, no passado, as contribuições que se deram no âmbito do racionalismo, o historiador se depara com os obstáculos que impediram a ciência de progredir mais rapidamente. É assim que, para Sarton, a história da ciência

pode sempre ser considerada sob dois aspectos: ou positivamente como a gradual revelação da verdade, o aumento de luz, ou negativamente como o triunfo progressivo sobre o erro e a superstição, a diminuição da escuridão. O cientista moderno, quando estuda a ciência medieval, tornase um pouco impaciente, porque está acostumado a um passo muito maior. Ele gostaria de ser capaz de observar o progresso da ciência, e por muitos séculos, o passo foi frequentemente muito lento, com tantas paradas e regressões, que a impressão que se tem é de que não houve progresso algum (SARTON, 1927, p. 25).

Enquanto historiador da ciência, Sarton (1927, p. 14) declara sua preferência pela ciência dos séculos XVIII e XIX, um período de "tremendo" progresso, e considera que quanto mais um historiador saiba sobre a ciência de seu tempo, tanto mais capacitado estará para avaliar aquela do passado (Cf. SARTON, 1957, p. 19). É curioso que Sarton afirme que, para se compreender as últimas conquistas da ciência, é necessário conhecer seu passado, (quando compara o desenvolvimento da ciência a uma árvore), e que, por outro lado, considere que, para melhor avaliar o conhecimento científico passado, o historiador deva estar bem familiarizado com a ciência de seus dias. No primeiro plano, a exigência é a de que o historiador esteja preocupado com toda a "árvore", ou seja, com toda a ciência em sua unidade, em "descobrir indutivamente as sequências lógicas ou soluções lógicas da continuidade nos argumentos e atividades que têm conduzido a humanidade de uma descoberta a outra, e, a partir

\footnotetext{
${ }^{13}$ Veja, por exemplo, Sarton (1962a, p. 137, 140; 1959c, p. 87; 1953, p. 17).

${ }^{14}$ Sobre esse episódio na obra histórica de Sarton, ver Pinto de Oliveira, J.C e Oliveira, A. J. (2018).
} 
de cada nível científico, a um mais elevado indefinidamente" (SARTON, 1957, p. 37-38). No segundo, há a convicção de Sarton (1957, p. 19) de que, sem um conhecimento suficiente da moderna ciência, o historiador não será capaz de compreender os primeiros estágios do conhecimento. Sarton, cuja perspectiva histórica é guiada pelos valores e padrões científicos que lhe são contemporâneos, poderia indagar: o que o historiador pesquisaria no passado, sem o conhecimento da ciência moderna?

O historiador da ciência "é um colecionador de ideias científicas, do mesmo modo que o entomologista é um colecionador de insetos, sendo a "coleção", em ambos os casos, somente o primeiro passo em direção ao conhecimento" (SARTON, 1957, p. 10). A similaridade entre ambos, segundo Sarton, está no fato de que os colecionadores precisam empregar métodos que assegurem que os itens selecionados sejam determinados de modo o mais inequívoco e determinado possível. O historiador selecionará os fatos científicos que concorreram para a busca da verdade, para o atual conhecimento científico. Quando esses fatos estão seguramente estabelecidos, ele retira suas conclusões e constrói, progressivamente, um sistema de conhecimento.

A analogia sartoniana entre o historiador e o entomologista faz lembrar a consideração, muitas vezes crítica, de muitos de seus intérpretes que o viram como compilador de fatos biográficos e bibliográficos do passado da ciência ${ }^{15}$. Em acordo com sua concepção historiográfica, Sarton se dedicou, por um lado a coletar os fatos que promoveram a descoberta da verdade e, de outro, a identificar os fatos vinculados a erros e superstições que atravancaram o desenvolvimento científico. Em comparação com as histórias de outras áreas, a história da ciência é a que apresentaria uma diferença muito menor entre narrações biográficas e não biográficas. Isso porque, de certo modo

a história da ciência é altamente individualista devido ao fato de que as grandes descobertas foram feitas geralmente por indivíduos sozinhos e frequentemente por homens imprevistos, em lugares inesperados. Não é possível explicar por que uma descoberta foi feita por este homem e não

\footnotetext{
${ }^{15}$ Ver, por exemplo, Alistair Crombie (1959, p. 164); Rupert Hall (1969, p. 215); Marshall Clagett (1957, p. 321) e Edward Grant (1987, p. 91). Nos escritos introdutórios de suas principais obras, Sarton demonstrou estar ciente desse aspecto e o atribuiu ao pioneirismo e à dimensão de seu empreendimento em constituir uma base sólida para o estudo em história da ciência.
} 
por outro; na Dinamarca e não da Itália e, o que é mais estranho: naquele tempo e não um pouco antes ou depois. Sem dúvida, há certo determinismo na sucessão das descobertas. A maior prova disso é a ocorrência não rara de descobertas simultâneas (SARTON, 1988, p. 20).

Sarton (1988, p. 20-21) não desconsidera, entretanto, certas particularidades em algumas descobertas, como a prontidão com que umas se apresentam; a lentidão de outras e a inversão da ordem lógica. Um exemplo discutido é a descoberta de Harvey, a da circulação do sangue, que teria "demorado" até o século XVII. A análise das obras dos grandes cientistas, entretanto, não é suficiente para a história da ciência, visto que as descobertas são, muitas vezes, preparadas por outros descobrimentos menores. E, se a investigação é levada adiante, outras etapas intermediárias são detectadas. É sob essa perspectiva que Sarton utiliza a metáfora da escada, aludida por Bernard Cohen para caracterizar a visão cumulativa e progressiva, conforme citada acima. Quando apenas os feitos dos grandes cientistas são considerados, os degraus parecem grandes; conforme se avança na investigação, outros vão se intercalando. No entanto, por mais longe que se leve a investigação, até mesmo ao ponto dos degraus desaparecerem, a análise "permanece individualista até o fim e, portanto, extremamente humana” (SARTON, 1988, p. 22).

Sarton fala da oposição entre a perspectiva continuísta e a descontinuísta, aparentemente cônscio da discussão existente na historiografia da ciência após os trabalhos de Pierre Duhem e de seus críticos $^{16}$. A alternativa entre continuidade e a descontinuidade é discutida em sua obra, com clara opção para a primeira, sob o argumento de que

devemos conceber a Antiguidade, a Idade Média ou qualquer outro período, não como exclusivos, mas como sobreposições. Nunca houve uma descontinuidade nítida, nem haverá qualquer descontinuidade em minha narrativa. Desse modo, o leitor poderá testemunhar os tempos antigos desvanecendo imperceptivelmente em direção à Idade Média (SARTON, 1927, p. 14).

\footnotetext{
${ }^{16}$ Figura importante neste contexto é Alexandre Koyré que critica a tese da continuidade de Duhem. Ver, por exemplo, Koyré (1966 [1939], p. 15-16; 1973 [1943]. p. 171-172). Há de ser lembrado ainda que Sarton participou do mesmo congresso em comemoração ao V centenário do nascimento de Leonardo da Vinci realizado em Paris, cujos trabalhos apresentados estão reunidos em Léonard de Vinci \& l'expérience scientifique au seizième siècle, editado por Febvre et al (1953). O livro revela a controvérsia gerada pela obra duhemiana Études sur Léonard de Vinci, publicado em três volumes entre 1906 e 1913, um trabalho importante na argumentação de Duhem em prol da continuidade da ciência. Sobre a controvérsia em torno da obra de Leonardo de Vinci, ver Oliveira (2016).
} 
Quase vinte anos mais tarde, no texto "The Study of Early Scientific Textbooks”, publicado originalmente em 1948, Sarton (1962a, p. 340) indaga: "Devemos enfatizar as descontinuidades, as revoluções da história ou sua essencial continuidade?” Aí afirma que as duas visões se completam para a boa compreensão da história da ciência. As descontinuidades devem ser descritas, mas nenhuma descrição histórica estaria completa, se a continuidade não servir de base. O historiador deve louvar os grandes heróis e mostrar suas grandezas, mas não pode se esquecer das outras pessoas, entre as quais eles realizaram seus feitos, contra as quais apresentaram suas ideias. As grandes descobertas ou revoluções intelectuais têm um processo longo de incubação. Pode-se observar que Sarton, aqui, não vê a alternativa entre continuidade e descontinuidade como exclusiva, mas como complementar. Essa perspectiva não é contraditória com a afirmação de que o leitor não encontrará em sua Introduction qualquer descontinuidade. Na elaboração de sua narrativa, ele é o historiador que buscou fornecer a história contínua do progresso humano. Ao mesmo tempo, saudou os heróis e seus grandes feitos; comparou épocas, assinalando para o caráter diferenciador de algumas delas. É assim que, em relação à Renascença, ele afirma:

No campo das ciências, as novidades eram gigantescas, revolucionárias. [...] Nada pode ser mais revolucionário do que o crescimento do conhecimento. A ciência está na raiz de toda mudança social. Os cientistas da Renascença introduziram não um "novo olhar", mas um novo ser. As novidades eram frequentemente tão grandes que dificilmente se poderia falar de uma Renascença ou de um renascimento; foi um nascimento real, um novo começo (SARTON, 1962b, p. 57).

Note-se que Sarton emprega as expressões "revolucionárias", "revolucionário" em relação ao aumento grande do conhecimento. A ideia de revolução associada a uma aceleração do progresso científico aparece em outros textos de Sarton ${ }^{17}$. Agora, como conjugar a ideia de continuidade com a afirmação de que a Renascença foi "um nascimento

\footnotetext{
${ }^{17}$ Em The Study of History of Science, Sarton (1957, p. 20) combate a visão de que a "real" ciência tenha se iniciado somente no século XVII ou XVI, mas insiste na aceleração do progresso científico ocorrida no período. Em "História da ciência”, Sarton (1962a, p. 6) lista algumas das descobertas científicas revolucionárias que ocorreram no século $\mathrm{XX}$, atribuindo-lhes, sobretudo, o rápido desenvolvimento e intensa difusão.
} 
real, um novo começo"? Aqui novamente há de ser lembrado que, do ponto de vista da narrativa histórica, não há descontinuidade: segue-se gradualmente da idade média para a Renascença e depois para a Idade Moderna, o que não implica no impedimento de se comparar épocas, estágios do desenvolvimento da ciência e de concebê-los como revolucionários, em contexto em que "revolucionários" tem um significado singular. A questão que permanece é: em que medida e como a singularidade desse significado distancia a visão sartoniana da de outros historiadores, como Conant e Kuhn. Como já comentado acima, é curioso que algumas afirmações de Sarton, tomadas isoladamente, parecem estranhas à obra de um autor que é visto invariavelmente como um descrente em revoluções. E não é à toa. Há, em sua obra, mais do que simples afirmações sugestivas acerca de revoluções científicas. Além da passagem mencionada acima sobre a Renascença, tome-se, como exemplo, a seguinte consideração:

[...] qualquer ramo da ciência pode ser completamente revolucionado a qualquer tempo por uma descoberta, requerendo uma abordagem radicalmente nova do assunto. A química de hoje é essencialmente diferente da química no século XVIII. As noções fundamentais são diferentes, o âmbito inacreditavelmente maior e os conteúdos infinitamente mais variados. [...] o crescimento dos conteúdos científicos é imprevisível, impressionante e algumas vezes explosivo em sua intensidade e destrutividade (SARTON, 1957, p. 7-8) ${ }^{18}$.

Se em sua mais famosa obra, Sarton enfatizou a continuidade da ciência - e aqui não pode ser ignorado o fato de que sua Introduction compreendeu a história da ciência somente até o século XIV - é possível encontrar menções a revoluções em seus outros escritos que acenam para a percepção de mudanças radicais na ciência. Que ele não tenha se ocupado da tentativa de compreendê-las ou discuti-la é outra questão, que foge ao escopo da discussão deste texto. No entanto, é evidente que Sarton não negou e tampouco ignorou os eventos a que os historiadores se referiram comumente como revolucionários. Isso pode ser verificado também na sua

\footnotetext{
${ }^{18}$ Em outro texto, Sarton (1988, p. 48) afirma: “O espírito científico é a maior força de construção, mas também de destruição”. É interessante notar que Kuhn (1977, p. 208) também registrou o caráter destrutivo de uma revolução científica, ao afirmar: "a aceitação de uma nova teoria requer a rejeição de uma mais velha. No domínio da teoria, a inovação é, deste modo, necessariamente tanto destrutiva como construtiva”.
} 
observação sobre o feito newtoniano. Diz Sarton (1988, p. 40): "Quanto ao Principia, esse foi realmente a pedra de fundação do pensamento moderno. Nossa concepção de mundo foi completamente mudada por ele; isto é, o mundo mesmo mudou". Em The Life of Science, lemos:

\begin{abstract}
Guerras e revoluções não são essencialmente diferentes de catástrofes naturais [...] Para a maioria dos homens essas catástrofes são os eventos mais importantes e isso é bastante natural, uma vez que seu bem estar é afetado terrivelmente por elas. As descobertas de Galileu ou Newton não elevaram o preço da comida ou de abrigo, ao menos com suficiente rapidez para ser perceptível. Para nós, ao contrário, essas descobertas que, mais cedo ou mais tarde, deviam transformar a perspectiva do homem e, por assim dizer, expandir tanto o universo quanto a si mesmo, são os eventos principais da história do mundo (SARTON, 1948, p. 64).
\end{abstract}

Como se pode observar, enquanto historiador, Sarton afirmou a importância da revolução científica, apesar de não ter publicado estudos sobre ela, como fizeram seus contemporâneos. Assim, sua defesa da continuidade da ciência não se choca com a percepção de mudança revolucionária, ainda que - devemos lembrar - "revolução" não seja uma expressão discutida metodicamente por ele, da mesma maneira como ele também não se preocupa em caracterizar a noção de continuidade no conjunto de sua obra. Tanto é verdade que ele não emprega o termo "contínuo" (ou expressões equivalentes) em seu "teorema”. O que lhe é relevante é a noção de ciência enquanto conhecimento positivo sistematizado, que progride cumulativamente, isto é, pela adição de verdades. E a preocupação em explicitar esse seu ponto de vista, como vimos, permite-lhe definir o que é ciência (anacronicamente poderíamos falar que lhe serve como "um critério de demarcação") e em que consiste a tarefa do historiador: de um lado, identificar, agrupar e organizar cronologicamente a soma de verdades e, de outro, identificar os obstáculos para a acumulação. Em termos sartonianos, ao historiador da ciência, cabe expor a luta contínua entre a razão e a desrazão, numa tarefa em que acumula verdades e identifica os erros, mitos etc., que não tomam parte do corpo de conhecimento denominado "ciência”, um conceito instituído a partir dos valores e padrões científicos vigentes em seu tempo. 


\title{
III. O conhecimento cumulativo em Conant
}

As obras de Conant em história e filosofia da ciência exprimem seu empreendimento em promover a compreensão da ciência entre leigos e se relacionam diretamente ao seu projeto "The Harvard Case Histories in Experimental Science", um empreendimento baseado no estudo de casos relevantes na história da ciência moderna, em fins dos anos 40. Na introdução do volume I da obra que reúne as narrativas históricas de grandes experimentos científicos, Conant afirma que esses estudos

\begin{abstract}
foram projetados inicialmente para estudantes graduandos em humanidades e ciências sociais. Tais estudantes necessitam de um entendimento da ciência que os ajudará a relacionar os desenvolvimentos da ciência natural àqueles dos outros campos da atividade humana. Fazer isso requer um entendimento tanto dos métodos da ciência experimental quanto do crescimento da pesquisa científica como uma atividade organizada da sociedade (CONANT, 1957b, p. vii).
\end{abstract}

Posteriormente, a publicação dos dois volumes da série visou atingir o público em geral. As narrativas históricas são focadas na história da ciência a partir do século XVII, para a qual Conant não deixa de assinalar um papel significativo para a compreensão do mundo moderno. A caracterização da ciência como "conhecimento cumulativo" é reiterada em seus escritos. É assim que em On Understanding Science, ele dedica uma seção para essa discussão. E aí "conhecimento cumulativo" comporta diversas áreas, como matemática, física, química, biologia, antropologia, filologia e arqueologia. O critério para o agrupamento dessas áreas enquanto cumulativas, segundo Conant (1951 [1947] , p. 34), é o inegável avanço que tiveram nos últimos três séculos.

A noção de acumulação está vinculada estritamente ao progresso e não se aplica a outras áreas que não apresentaram avanço objetivo no tempo, como a filosofia e arte. Para argumentar em favor dessa ideia, Conant convida o leitor a imaginar uma situação em que fosse possível trazer de volta, à vida, importantes figuras do passado e indagar pela existência ou não de avanço em suas áreas. As respostas de Galileu, Newton e Harvey seriam definitivamente afirmativas, o que não aconteceria se a mesma pergunta fosse dirigida a Michelangelo, Rembrandt e outros artistas. Diferentes ainda seriam as repostas de 
Tomás de Aquino, Spinoza, Locke ou Kant. Em filosofia e arte, as respostas não seriam unânimes.

A noção de progresso é introduzida por Conant (1951, p. 34) como "um método de definição de uma área da atividade intelectual” e não pressupõe qualquer hierarquia entre essas atividades ${ }^{19}$. Essa definição, ele afirma, não emerge de uma análise lógica da ciência, como aquela elaborada por filósofos, mas é esboçada em termos do desenvolvimento histórico:

Como uma primeira aproximação, nós podemos dizer que a ciência emerge de outras atividades progressivas do homem ao estender aqueles novos conceitos que surgem a partir de experimentos e observações. [...] A trama da ciência moderna é o resultado do entrelaçamento de conceitos frutíferos. O teste de uma nova ideia é, portanto, não somente seu sucesso em correlacionar os fatos então conhecidos, mas muito mais seu sucesso ou falha em estimular experimentação ou observação posterior que, por sua vez, é frutífera (CONANT, 1951, p. 37).

Essa caracterização remete à recorrente definição da ciência de Conant (1972 [1951], p. 25, 47) como "uma série interconectada de conceitos e esquemas conceituais", que dela faz um empreendimento especulativo incessante. As novas ideias e o significado de novas descobertas científicas têm sua validade apreciada pelas suas consequências, que são, por sua vez, novas ideias e novos experimentos (Cf. CONANT, 1972, p. 24-25). A essa visão, que classifica de "dinâmica", Conant contrapõe a visão "estática", segundo a qual a ciência é vista como "o conjunto interconectado atual de princípios, leis e teorias, junto com a vasta ordem de informação sistematizada”.

A fim de caracterizar a visão dinâmica da ciência, Conant (1951, p. 38) se propôs a escolher estudos de casos da história da ciência em diversas áreas de todo o campo do conhecimento cumulativo e estabelece três critérios: (1) que o campo do conhecimento escolhido tenha apresentado indubitável progresso no último século; (2) que esse progresso não seja analisado em termos de empreendimentos práticos nem pela mera acumulação de dados, mas, sim, em termos de mudanças

\footnotetext{
${ }^{19}$ Essas colocações sobre o conhecimento cumulativo são encontradas também na obra posterior de Conant, Science and Common Sense, no segundo capítulo "O que é a ciência?", em uma seção denominada "conhecimento cumulativo" (CONANT, 1972, p. 37-39).
} 
de conceitos, envolvendo esquemas conceituais, os resultados de experimentos e observações que levam a novos experimentos e observações; e (3) que o estudo de caso deve ilustrar um ou mais princípios comuns "à Tática e Estratégia da Ciência” ${ }^{20}$. Ele justifica o uso dessa expressão recorrendo à analogia do ensino da estratégia e tática de guerra a partir de exemplos da história militar. Como o sucesso desse procedimento educacional é bem sucedido naquele campo, poderia ser também útil para a compreensão do empreendimento científico. No capítulo 4 de On Understanding Science, Conant apresenta uma síntese de sua caracterização de ciência:

Aventurei-me a definir ciência [...] como aquela porção de conhecimento acumulativo no qual novos conceitos se desenvolvem continuamente a partir de experimento e observação e conduzem a outros experimentos e observações. É neste sentido da palavra, portanto, que a expressão "os princípios da Tática e Estratégia da Ciência” é usada (CONANT, 1951, p. 102).

Com os exemplos retirados de cada caso estudado, com foco na história da química, Conant apresenta, em On Understanding Science, alguns dos princípios da tática e estratégia da ciência. A revolução química aparece-lhe como um exemplo privilegiado para discorrer sobre o desenvolvimento de um novo esquema conceitual ${ }^{21}$. Diz Conant:

A superação da teoria do flogisto envolveu o desenvolvimento de um esquema conceitual superior. Não pode haver dúvida de que o autor das novas ideias foi o químico francês Lavoisier, frequentemente mencionado como o "pai da química moderna”. Contudo, a revolução química não aconteceu de um dia para o outro e Lavoisier não obteve seus resultados isoladamente. Ao estudar a evolução de um novo esquema conceitual, podemos ver as dificuldades com as quais os pioneiros na ciência quase sempre têm de lutar e os falsos passos que usualmente acompanham até mesmo as marchas progressivas mais bem sucedidas (CONANT, 1957b, p. 67).

\footnotetext{
${ }^{20}$ Conant (1951, p. 38) esclarece que esses critérios eliminam estudos de arqueologia, filologia e métodos de avanço no conhecimento histórico.

${ }^{21}$ Em The Harvard Case Histories in Experimental Science, ver caso 2, "The Overthrow of the Phlogiston Theory"; em On Understanding Science, ver capítulo III e em Science and Common Science, o capítulo 7.
} 
Conant (1972, p. 165) assegura que o modo mais fácil de compreender a revolução química associada o nome de Lavoisier requer, em primeiro lugar, a descrição do fenômeno da combustão em termos modernos e a explicação de como, por aproximadamente cem anos, outras ideias prevaleceram. Antes de traçar o caminho percorrido por Lavoisier que o conduziu a seu novo esquema conceitual, é necessário saber onde ele começou. Em sua narrativa, Conant mostra como um conceito tão importante na ciência, como "flogisto", passa a ser quase desnecessário com o surgimento de um novo esquema conceitual. Mostra ainda como os contemporâneos de Lavoisier se mantiveram resistentes ao abandono da teoria, o que exemplifica a tenacidade dos cientistas na manutenção de velhas ideias (Cf. CONANT, 1972, p. 167).

A teoria do flogisto, em sua abordagem, constituiu um avanço no desenvolvimento da química e foi amplamente aceita porque "flogisto" era um "conceito que fornecia um padrão dentro do qual um conjunto de fenômenos, não relacionados de outra forma, poderia ser ajustado" (CONANT, 1972, p. 169). Apesar de Conant afirmar a necessidade de empregar uma linguagem moderna para conduzir sua narrativa histórica, ele parece preocupado em não atribuir à análise de um esquema conceitual ultrapassado (no caso, o do flogisto) os valores e padrões da moderna química. É assim, por exemplo, que afirma:

Boyle confirmou o aumento de peso dos metais na calcinação em 1673, mas não adicionou nenhum suporte ao achado perspicaz de Rey [...] No mínimo, em retrospecto, parece que, se ele tivesse seguido seus próprios experimentos somente um pouco mais audaciosamente, a teoria do flogisto poderia nunca ter sido proposta ou, se proposta, nunca teria sido aceita seriamente. Contudo, é fácil demais construir história imaginária. Duvido que até mesmo um grande gênio como Boyle poderia ter descoberto o oxigênio e revelado seu papel na combustão e calcinação no século XVII. Tanto a física quanto a química estavam sob invólucros que só seriam vagarosamente removidos pelo trabalho de muitos homens (CONANT, 1972, p. 172). ${ }^{22}$

\footnotetext{
${ }^{22}$ A descoberta do aumento de peso dos metais na calcinação, realizada por Rey e ignorada por 150 anos, é mencionada por Conant em nono lugar na sua lista dos "princípios da Tática e Estratégia da Ciência" em On Understanding Science e prescreve que "uma descoberta científica deve se ajustar aos tempos" (CONANT, 1951, p.106).
} 
A análise da passagem do esquema conceptual antigo ao de Lavoisier mostra, afirma Conant, que um esquema conceitual nunca é descartado simplesmente porque um fato não se ajusta a ele. Ou ele é modificado ou substituído por um melhor; nunca é abandonado sem que haja outro a tomar o seu lugar. Quando analisa a teoria do Flogisto, ele afirma:

O princípio estratégico que emerge é claro: ele leva um novo esquema conceitual a causar o abandono de um velho. Quando somente alguns fatos parecem ser irreconciliáveis com um esquema conceitual bem estabelecido, a primeira tentativa é não abandonar o esquema, mas procurar encontrar uma saída e mantê-lo. Da mesma maneira, os preponentes de novos esquemas conceituais raramente são abalados por alguns fatos alegados ao contrário (CONANT, 1972, p. 181-182).

A mudança revolucionária na química, segundo Conant (1957c, p. 67-68) pode ser analisada em quatro estágios, dos quais ele seleciona um para discutir mais detalhadamente em seu estudo de caso - "a descoberta efetiva do oxigênio, o desenrolar de suas relações com a calcinação de metais no ar e seu papel na respiração de animais, 1774 -1778”. A efetivação da revolução química, em sua visão, ocorre em 1789, com a "extensão e formulação precisa de um novo esquema conceitual em termos de uma nova nomenclatura química no Traité Élémentaire de Chimie, de Lavoisier".

Como se pode notar, Conant caracterizou a ciência como conhecimento cumulativo em estreita conexão com a noção de esquema conceitual. A superação de um esquema conceitual, como a ocorrente na história da química, é abordada como um feito revolucionário. Nesse sentido, a correlação entre a caracterização da ciência como conhecimento cumulativo e a negação de revolução no desenvolvimento da ciência não faz qualquer sentido em sua perspectiva histórica.

Em um texto publicado em 1964, Conant volta a evocar sua definição de ciência, lembrando que a definição "não satisfaz a certas pessoas" que desejam "igualar a ciência à busca da estrutura última do universo, o que as leva a distinguir a ciência da arte ou poesia pela natureza cumulativa do conhecimento científico" (CONANT, 1968 [1974], p. 46). E aí ele se reporta a Kuhn, por sua defesa, em $A$ estrutura das revoluções científicas, de que "a história da ciência não comprova esse ponto de vista 
tão largamente aceito”. E embora reitere sua convicção de que o trabalho dos cientistas seja diferente do dos artistas e poetas, ele afirma concordância com o ponto de vista kuhniano de que é "errôneo medir as conquistas da ciência pelo grau em que nos aproximariam de algum alvo último" (CONANT, 1968, p. 46).

É possível notar que, embora fale da ciência como conhecimento cumulativo, Conant parece discordar de alguns supostos continuístas que veem a finalidade da ciência como busca de uma descrição última da realidade:

As revoluções científicas envolvem tão drásticas reorientações dos modos de pensar dos cientistas, que a ideia de um processo contínuo em longos períodos de tempo dificilmente pode ser sustentada. Em cada época, os homens interessados nos fenômenos da natureza adotam o que lhes parece "o esquema conceitual mais simples em que se ajustam e ordenam os fragmentos desordenados da nossa experiência imediata”, para citar o professor W.V.O. Quine, que acredita "não ter sentido inquirir sobre a absoluta correção de um esquema conceitual como espelho da realidade" (CONANT, 1972, p. 46-47).

Essas colocações de Conant sugerem, mais uma vez, uma diferenciação do modo como ele concebe o conhecimento cumulativo, que não se equipara à noção de progresso por acumulação gradativa ao longo de todo o desenvolvimento da ciência (o que ele identifica "processo contínuo em longos períodos de tempos”). O conhecimento é cumulativo em função de um esquema conceitual suplantar o outro e se revelar superior ao anterior. A noção de cumulativismo está estritamente relacionada ao aumento do conhecimento, mas não ao aumento gradativo rumo a uma verdade última e objetiva. É assim que ele demonstra maior interesse no estudo da história da ciência moderna - um período de grandes avanços, de grande acúmulo de conhecimento gerado pela emergência de novos esquemas conceituais. Como se pode observar, a noção de "conhecimento cumulativo" em Conant não nega a ocorrência de revoluções em ciência, mas a pressupõe. 
844 | Veritas | Porto Alegre, v. 63, n. 3, set.-dez. 2018, p. 822-855

\section{O conhecimento cumulativo em Thomas Kuhn: a antiga e nova historiografia}

A ciência cresce por acumulação, mas não só dessa maneira. $\mathrm{O}$ crescimento cumulativo está circunscrito ao período de ciência normal uma tradição consensual de pesquisa guiada por um paradigma. A mudança científica que ocorre nesse âmbito é o de acréscimo ao que já era antes conhecido. Grosso modo, essa é a perspectiva de Kuhn, para quem as leis científicas são um produto do desenvolvimento normal, cumulativo, da ciência. Como exemplo, ele cita a lei de Boyle: "seus descobridores já possuíam anteriormente os conceitos de pressão de gás e volume, bem como os instrumentos exigidos para determinar suas magnitudes" (KUHN, 200o, p. 14). Muito dos avanços científicos se processam dessa maneira, "normal cumulativa". Kuhn esteve empenhado em mostrar que a mudança na ciência não se processou desta maneira em toda sua história. A mudança pode ser também revolucionária, quando há mudanças de teorias, caso em que as descobertas "não podem ser acomodadas dentro dos conceitos que estavam em uso antes que elas tivessem sido realizadas" (KUHN, 2000, p. 14).

Embora alguns conceitos científicos estejam disponíveis desde a antiguidade, como, por exemplo, o de "elemento", isso não significa que a química tenha progredido cumulativamente deste então. Boyle e Lavoisier modificaram substancialmente essa noção e a compreensão do desenvolvimento da química pressupõe o reconhecimento da mudança que "transformou a noção em uma ferramenta completamente diferente do que ela tinha sido antes e transformou, no processo, tanto a química quanto o mundo do químico" (KUHN 1970b, p. 143) ${ }^{23}$.

A principal crítica de Kuhn com relação à visão cumulativa, não condizente àquela identificada na ciência "normal", mas tomada globalmente na história da ciência, é a de que ela torna as revoluções científicas invisíveis, gerando uma imagem da ciência bastante distorcida. Essa imagem é a fornecida nos manuais científicos, nos textos de divulgação e os trabalhos filosóficos baseados em manuais, que eram até recentemente - ele o afirma em 1962 (KUHN, 1970b, p. 136) - as únicas fontes de informação sobre a ciência, além da prática de pesquisa. Essas

${ }^{23}$ Sobre a mudança conceitual na química segundo a perspectiva histórica kuhniana, ver Oliveira (2015). 
fontes partilham de uma característica comum: eles apresentam um corpo de problemas, de dados e teorias relacionados a um conjunto particular de paradigmas vigentes na época em que foram escritas. É dessa maneira, diz Kuhn (1970b, p. 137), que elas "registram o resultado estável das revoluções passadas e assim mostram as bases atuais da tradição científica normal”.

Em conformidade com os parâmetros e valores da ciência vigentes, a escrita de manuais foi guiada por uma imagem de ciência fixa, que busca no passado somente os fatos contributivos para a sua atual formação. A história da ciência tenderia a ser o empreendimento que registra o acúmulo de fatos, teorias e métodos sucessivamente, ao mesmo tempo em que expõe os entraves que impediram a acumulação. Na perspectiva de que a ciência se desenvolva somente por acumulação, o historiador, segundo Kuhn (1970b, p. 2), teria então duas tarefas: por um lado, identificar, no passado, o nome e a data do inventor ou descobridor dos fatos, leis e teorias em voga e, por outro lado, ele deveria descrever e explicar o montante de erros, mitos e superstições que atrapalham uma acumulação mais rápida dos elementos que compõem o texto da moderna ciência.

Mas a história, assim descrita, não estava ilesa a mudanças quando Kuhn discorre sobre suas características, já que, ao mesmo tempo em que a caracterizava, ele reconhecia a ocorrência de uma revolução historiográfica, ainda que em seus primeiros estágios. Diz Kuhn:

Nos anos recentes, contudo, alguns historiadores da ciência têm encontrado cada vez mais dificuldades para preencher as funções que o conceito de desenvolvimento por acumulação lhes atribui. Enquanto cronistas de um processo incremental, eles descobrem que a pesquisa adicional torna mais difícil e não mais fácil, responder a questões como: Quando o oxigênio foi descoberto? [...] Ao mesmo tempo, esses mesmos historiadores se deparam com dificuldades crescentes para distinguir o componente "científico" da observação e crença do passado daquilo que seus predecessores tinham prontamente rotulado de "erro" e "superstição". Quanto mais cuidadosamente eles estudam, digamos, a dinâmica aristotélica, a química flogística ou a termodinâmica calórica, mais certos eles se sentem de que essas visões da natureza, um dia vigentes, não eram, em seu conjunto, 
nem menos científicas nem mais que o produto da idiossincrasia humana do que aquelas vigentes hoje [...] Teorias ultrapassadas não são, em princípio, acientíficas porque foram descartadas (KUHN, 197ob, p. 2-3).

Sob essa nova perspectiva histórica, da qual Kuhn elege como principal representante Alexandre Koyré, a ciência não apresentava a mesma caracterização encontrada nas histórias da ciência mais antigas e sugeria a possibilidade da emergência de uma nova imagem de ciência, da qual Kuhn mostra-se não só como adepto, mas como um contribuidor em potencial. Para obter uma nova noção de ciência, era necessário, pois, uma nova historiografia da ciência. E o novo historiador da ciência não devia mais investigar, no passado, as contribuições para a constituição da ciência de seu momento presente, mas, ao invés disso, procuraria visualizar, nas teorias ultrapassadas, coerência e integridade ${ }^{24}$. Assim, veria que a ciência, no curso de sua longa história não progrediu por um processo de mera acumulação, mas também por meio de revoluções. Aliás, no livro em que apresenta um modo alternativo de olhar para o passado da ciência e que tem gerado intenso debate sobre o desenvolvimento da ciência, incluindo a controvérsia entre continuísmo/cumulativismo versus descontinuísmo, Kuhn (1970b, p. 16o) sugere, no último capítulo, que apresentou a "estrutura de uma evolução contínua da ciência”. A associação entre continuidade e cumulatividade não faz parte da teoria kuhniana, assim como não há nela qualquer antagonismo entre "evolução" e "revolução"25.

É sabido que Kuhn não fornece em seu livro mais famoso nenhuma indicação de nomes representantes da historiografia mais antiga que critica. Porém, é sabido também que, em seus textos posteriores, o nome de Sarton aparece associado a uma tradição "que via como o avanço científico como o triunfo da razão sobre a superstição primitiva” (KUHN, 1977, p. 148). Kuhn, que apesar de reconhecer o trabalho intenso de Sarton para a fundação da disciplina de história da ciência, considerou que a visão

\footnotetext{
${ }^{24}$ Kuhn se reporta, em seus escritos, diversas vezes, à experiência a que comumente se refere como "a experiência com Aristóteles”. Tendo de preparar um curso panorâmico sobre a mecânica, leu os textos aristotélicos, como muitos o fariam, tendo em mente a mecânica newtoniana e não encontrou inicialmente qualquer característica científica na obra do filósofo antigo. A descoberta posterior de que Aristóteles tinha sido, na verdade, um físico muito bom, mas muito diferente pela atual concepção de física, o fez descobrir sua primeira revolução científica. Relatos dessa experiência são encontrados em Kuhn, 1977, p. xi-xii; 2000, p. 15-17). Outras menções a esse episódio são encontradas em Kuhn, 200o, p. 59, 275, 278, 292.

25 Ver Oliveira (2012, p. 237).
} 
que ele propagou da ciência continuou a "causar muito prejuízo" (KUHN, 1977, p. 148); que, durante o tempo em que foram contemporâneos em Harvard, Sarton estava fazendo um tipo de história no qual ele não estava interessado; que ele era um historiador Whig ${ }^{26}$, "que via a ciência como a maior realização humana e o modelo para tudo mais”, que era um historiador de manuais, de quem poderia ter apreendido um monte de dados, mas não as coisas que queria aprender (KUHN, 2000, p. 282).

Preston (2008, p. 8o-81), que cita a famosa definição de Sarton mencionada na seção II, caracteriza o historiador como representante de uma visão whig, defensor da visão do desenvolvimento científico não só como progressivo, mas também como cumulativo ${ }^{27}$, em oposição à visão de Koyré e Butterfield. A menção de Preston ocorre quando ele comenta as explicações kuhnianas de por que as revoluções científicas parecem invisíveis. A visão de Sarton é tomada como exemplo do tipo de concepção que tornaria as revoluções invisíveis na história da ciência, porque aborda o passado a partir perspectiva privilegiada da ciência contemporânea. Mas, note-se, a visão cumulativa aqui não está (nem deveria estar) baseada na assunção de que Sarton tenha negado a ocorrência de revoluções em ciência. Poder-se-ia, no máximo, ser alegado que a concepção de revolução sartoniana era distinta daquela defendida posteriormente por Kuhn. Isso é evidentemente claro já que a abordagem kuhniana de revoluções se distingue daquela apresentada por outros historiadores da ciência, mesmo os que focavam seus trabalhos em revoluções científicas ${ }^{28}$.

Assim, a visão de Sarton pode, de fato, ser tomada como representante da concepção de que a ciência se desenvolve por acumulação, não porque ele tenha negado a ocorrência de revoluções, nem porque tenha defendido a continuidade histórica da ciência (da qual nem mesmo Kuhn discordaria), mas por se basear numa perspectiva histórica guiada pelos padrões da ciência vigentes em seu tempo.

\footnotetext{
${ }^{26} \mathrm{O}$ adjetivo whig, estabelecido por Herbert Butterfield em The Whig Interpretation of History (1965 [1931]) para qualificar a interpretação de fatos históricos com referência a valores e padrões contemporâneos, parece-nos o ponto mais alto da crítica de Kuhn a Sarton. Ver Kuhn (2000, p. 282).

${ }^{27}$ Pinto de Oliveira, J.C e Oliveira, A. J. (2018) argumentam em favor da ideia de que Sarton pode ser tomado como um típico representante da história criticada por Kuhn, a história de manuais, em sua oposição entre a historiografia mais antiga e a nova historiografia.

${ }^{28}$ Em prol dessa afirmação, observe-se as ressalvas kuhnianas em relação ao trabalho de Koyré, discutidas por Pinto de Oliveira (2012, p. 118-119). Kuhn apresenta ainda ressalvas à visão de Butterfield (ver KUHN, 1952a, p. 14, n. 13 e KUHN, 1977, p. 35, n.3; 131, n.2) e Bernard Cohen (ver KUHN, 2000, p. 283).
} 
E quanto a Conant? Além das considerações de reconhecimento demonstradas por Kuhn em relação a ele ${ }^{29}$, relacionadas à sua inserção na história da ciência, à troca de ideias e ao trabalho colaborativo, além do fato de Conant ter escrito a introdução a The Copernican Revolution, muitos intérpretes têm apontado confluências não negligenciáveis entre suas visões de ciência e seus trabalhos históricos ${ }^{30}$. Há de ser lembrado ainda que Kuhn (1970a) trata a revolução copernicana como a passagem de um esquema conceptual a outro, o que remete claramente à abordagem de Conant quando trata a revolução química como a superação de um esquema conceptual por outro ${ }^{31}$. Aliás, Kuhn remete o leitor, diversas vezes, ao texto de Conant, The Overthrow of the Phlogiston Theory, para referendar a argumentação pretendida em partes de sua obra ${ }^{32}$. Devemos lembrar que os primeiros textos de Kuhn ${ }^{33}$, um físico que começou a se interessar por história da ciência, abordam a história da química, área de formação de Conant. Vale lembrar ainda que a revolução química ocupa um espaço bastante significativo em $A$ estrutura das revoluções científicas, quando Kuhn cita o trabalho de Conant para corroborar suas ideias acerca da estrutura de uma revolução. Aliás, uma das referências ocorre quando Kuhn (1970b, p. 99-100) discorre sobre a teoria do flogisto, vista como um entrave pela historiografia mais antiga ${ }^{34}$, mas agora discutida como um estágio profícuo na história da ciência.

Quando observamos esses aspectos, não resta dúvida de que lado estariam Sarton e Conant quando Kuhn estabelece uma distinção entre uma história da ciência mais antiga, carente de superação e uma emergente nova historiografia. Assim, a expressão "conhecimento

\footnotetext{
${ }^{29}$ Ver Kuhn (197ob, xi; 2000, p. 259, 275).

${ }^{30}$ Ver, por exemplo, Marcum (2005, p. 30-33); Hoyningen Huene (1993, p. 167, n1; 199-200, n 13; 237, n.82; 258, n. 190); Pacheco (2011).

${ }^{31}$ Swerdlow (2004) discute a influência de Conant sobre a elaboração de The Copernican Revolution, de Kuhn. Pacheco (2011) apresenta um estudo comparativo entre as ideias de Kuhn e Conant e destaca justamente a "caracterização que ambos fazem da dinâmica histórica como a sucessão da unidade de análise que denominam de 'esquemas conceituais”' (p. 9). Curiosamente, após apresentar vários pontos de convergência entre eles, Pacheco assinala uma diferença significativa: o enfoque cumulativo do conhecimento em Conant face ao reconhecimento de Kuhn de momentos de descontinuidade, do progresso por revoluções (p. 12). Observações sobre o emprego de "esquemas conceptuais" por Conant e Kuhn são encontradas ainda em Westman (1994). Mayoral (2013, p. 464) afirma que para o "jovem Kuhn, o conhecimento é cumulativo” (como em Conant).

${ }^{32}$ Ver Kuhn (197ob, p. 54, n. 3; 6o, n. 9; 100, n. 3) e (1977, p. 167-168, n. 5; 169, n. 9 e 10; 210, n. 47).

33 Kuhn (1951, 1952a, 1952b e 1952c).

${ }^{34}$ Em seu texto "Boyle and Bayle the Sceptical Chemist and the Sceptical Historian", Sarton (1950, p. 167) refere-se à teoria do flogisto como um "fantasma" que interrompeu o progresso da química por um século.
} 
cumulativo", embora presentes em Conant e Sarton, não gera, em absoluto, uma igualdade de perspectiva histórica ou filosófica, como sugerida algumas vezes por seus intérpretes; e não gera pelo simples motivo de que os significados, como diz Kuhn, "são um produto histórico e mudam inevitavelmente ao longo do tempo” (KUHN, 20oo, p. 36).

\section{Considerações finais: "conhecimento cumulativo" de Sarton a Kuhn}

Mais de três décadas separam as publicações de Introduction to the history of Science, de Sarton, e a principal obra de Kuhn. Nesse meio tempo, muita coisa mudou na história da ciência, mas a mudança não ocorreu de um dia para outro e o próprio Kuhn, em "História da ciência" (1977, p. 105-126) esboça um quadro histórico em que a mudança se processou gradualmente. Nesse texto, em que ele não precisa argumentar em prol de uma nova historiografia em vista dos problemas apresentados na história da ciência mais antiga, o papel de Sarton na história da ciência aparece avaliado de maneira objetiva:

Um terceiro fator na formação da moderna historiografia da ciência tem
sido a repetida insistência de que o estudante do desenvolvimento
científico se preocupe com o conhecimento positivo como um todo e que
as histórias gerais substituam as histórias das ciências especiais [...] essa
exigência influenciou muito pouco as realizações eruditas antes do início
deste século quando foi energicamente reiterada pelo universalmente
venerado Paul Tannery e, então, posta em prática nas pesquisas
monumentais de George Sarton (KUHN, 1977, p. 109).

Kuhn avalia que a tentativa de se constituir uma história global da ciência não se mostrou viável, já que as ciências não podem ser concebidas como uma só e que nem mesmo uma erudição sobre-humana poderia dar conta da evolução de todas as ciências numa narrativa coerente. Contudo, reconhece que a tentativa foi "crucial" por que mostrou que é impossível atribuir, ao passado, as divisões existentes entre as disciplinas científicas contemporâneas (Cf. KUHN, 1977, p. 109).

Quando situa Sarton em uma tradição histórica que vai de "Condorcet e Comte a Dampier e Sarton", que "via o avanço científico como o triunfo da razão sobre a superstição primitiva”, Kuhn fornece, 
ainda que implicitamente, elementos para se compreender o empreendimento sartoniano. Quando iniciou seus trabalhos em história da ciência, Sarton pautou-se numa tradição (poderíamos dizer: pautou-se em um "esquema conceptual” ou em um "paradigma”), que, aos poucos, deu lugar a uma nova tradição, mas não antes de influenciar e contribuir para o empreendimento de historiadores, seja como exemplo, seja como contraexemplo. Isso pode ser observado nas considerações de Conant (1957a, p. 301-305), quando expõe que a convicção sartoniana em prol da importância do estudo histórico da ciência influenciou suas leituras, seus pensamentos e sua escrita, e também quando visualiza a distância das escolhas que fizeram, atribuindo a Sarton um anseio impraticável na realidade em que foram contemporâneos em Harvard.

Conant (1957a, p. 305) cita o "teorema sobre a história da ciência" de Sarton. A presença dessa citação em seu texto e as afirmações, em outros textos, de que o conhecimento é cumulativo não deveriam, por si só, serem tomados como indícios para um emparelhamento de suas visões no que se refere às suas concepções de progresso científico, ainda que a noção de progresso rápido esteja diretamente relacionada à definição de conhecimento cumulativo. Apesar de Conant e Sarton terem escrito narrativas históricas acerca de períodos distintos, não se pode ignorar o fato do primeiro não mencionar a obra do segundo em seus escritos históricos. Se a partilha da noção de conhecimento cumulativo fosse fato, os textos sartonianos seriam primordiais para Conant.

Como vimos, a expressão "cumulativo" em Sarton e Conant apresenta confluências. Ambos a caracterizaram em estreita conexão com o avanço experimental rápido, a sistematização e progresso humano. Por seu caráter cumulativo, a ciência foi vista por eles como uma atividade distinta das outras áreas do saber, da qual buscaram apresentar uma história de contribuições individuais. E a história da ciência passaria a ter uma importância em função da emergência da ciência moderna. Conectada à noção de progresso, "cumulativo" não exclui a ocorrência de revoluções em ciência.

Apesar das semelhanças, Conant reprovou o empreendimento sartoniano em prol de uma história da ciência global, para abordá-la como a história de esquemas conceituais. Desta maneira, Sarton e Conant não estão em posições antagônicas à de Kuhn porque negaram a ocorrência de revoluções científicas. Para Sarton, "revolução científica” é um 
desenvolvimento rápido que consiste em uma abordagem radicalmente nova dos fatos investigados; para Conant, a superação de um esquema conceitual por outro superior; para Kuhn a superação de um paradigma por outro. Suas visões são muito mais complexas para serem classificadas em tradições continuístas/cumulativistas ou descontinuístas, definidas a partir da ocorrência ou não de revoluções. A afirmação de que Sarton não foi adepto da crença em revoluções científicas, guiada pela aceitação da mudança historiográfica após Kuhn, é fruto de uma leitura anacrônica.

Como também vimos, "conhecimento cumulativo" em Kuhn está circunscrito à análise do desenvolvimento da ciência em sua fase normal. Se a visão histórica sartoniana pode ser tomada como antípoda da nova historiografia e, portanto, da visão historiográfica defendida por Kuhn, é por conta de sua visão whig. Sarton concebeu o desenvolvimento da ciência como uma grande adição de fatos, selecionados em função de uma perspectiva guiada por conceitos e padrões da ciência moderna. A história, por ele, foi concebida como o grande repositório de biografias e cronologias que exibe a continuidade dos empreendimentos científicos que conduzem a humanidade a um nível sempre mais elevado.

Já a noção de continuidade está presente tanto em Sarton, quanto em Conant e Kuhn, quando concebida de uma perspectiva histórica, não epistemológica. A abordagem dos esquemas conceituais de Conant e a de paradigma de Kuhn colocam em evidência a possibilidade de se pensar a continuidade histórica conjugada à descontinuidade epistemológica. Permite com que busquemos interpretar, por exemplo, a obra de Sarton em seus próprios termos. E se o fazemos, podemos perceber que as interpretações de Bernard Cohen e Preston sobre a história cumulativa possuem limites. A junção dos nomes de Sarton e Conant em uma tradição oposta a de Kuhn pode suscitar uma aproximação significativa entre os primeiros e um distanciamento forte entre Conant e Kuhn que não resistem a um exame mais apurado.

Em uma síntese, podemos conjecturar que Conant utiliza "conhecimento cumulativo" como uma expressão que estava à disposição na história da ciência ligada à noção de progresso, que, por sua vez, passou a estar presente de modo reiterado na tradição de pensadores após a revolução científica. Conant viu a ciência como um tipo de conhecimento, que após as grandes mudanças ocorridas a partir do século XVII, teve um avanço significativo na história do conhecimento humano, um aumento 
cumulativo. Porém, enquanto um estudioso de casos da ciência moderna, período de mudanças substanciais, acrescentou que o conhecimento cumulativo se desenvolve por meio uma sucessão de esquemas conceptuais interconectados, o que alterou substancialmente a concepção de conhecimento cumulativo disponível. Kuhn (1970a), que inicialmente também abordou uma revolução como mudança de esquema conceptual, circunscreveu a noção de conhecimento cumulativo, em sua obra posterior (KUHN, 197ob), ao período de ciência normal.

Essa síntese pode parecer um tanto grosseira, mas retoma aspectos, discutidos acima e muitas vezes negligenciados, quando se procura caracterizar o que é “conhecimento cumulativo". É assim que a resposta à questão que dá título a este trabalho só pode ser buscada quando se leva em consideração o contexto histórico de quem empregou essa expressão. O recorte "de Sarton a Kuhn", evidentemente arbitrário, ilustra a complexidade envolvida na análise de conceitos existentes na historiografia da ciência em um estágio de frutífero desenvolvimento desse campo.

\section{Referências}

AGASSI, J. Continuity and Discontinuity in the History of Science. Journal of History of Ideas. Vol. 34, $\mathrm{n}^{\circ}$ 04, 1973, p. 6o9-626.

ALFONSO-GOLDFARB, A. M.; BELTRAN, M.H.R. (orgs.) Escrevendo a história da ciência: tendências, propostas e discussões historiográficas. São Paulo: EDUC/Livraria Editora da Física/FAPESP, 2004.

BELTRÁN, A. Revolutión científica, Renacimiento e historia de la ciencia. Madrid: Siglo XXI de España Editores S.A, 1995.

BERNARD COHEN, I. Revolution in Science. Cambridge: Harvard University Press, 1994.

BERNARD COHEN, I. Alexandre Koyré in America: some personal reminiscences. In: REDONDI, P. (ed.) Science: the Renaissance of a history. History and Technology 4, 1-4, Proceedings of the International Conference - Paris, June 1986, p. 55-70. London: Harwood Academic Publishers, 1987.

BUTTERFIELD. H. The Whig Interpretation of History. New York: W W Norton \& Company, 1965.

CLAGETT, M. George Sarton: Historian of Medieval Science. Isis, Vol. 48, 3, p. 320-322, set. 1957 . 
A. J. Oliveira - O que é, afinal, conhecimento cumulativo? | 853

CONANT, J. B. On Understanding Science. An Historical Approach. New Haven: Yale University Press, 1951.

CONANT, J. B. George Sarton and Harvard University. Isis, The George Sarton Memorial Issue, set., p. 301-305, 1957a.

CONANT, J. B. (ed.). Introduction. In: CONANT, J. B. (ed.) Harvard Case Histories in Experimental Science, Cambridge, MA: Harvard University Press. 1957b.

CONANT, J. B. The Overthrow of the phlogiston. In: CONANT, J. B. (ed.) Harvard Case Histories in Experimental Science, Cambridge, MA: Harvard University Press. $1957 \mathrm{c}$.

CONANT, J. B. Dois modos de pensar: meus encontros coma ciência e a educação. Trad. Anísio Teixeira. São Paulo: Editora Nacional, 1968.

CONANT, J. B. Science and Common Sense, New Haven: Yale University Press, 1972.

CROMBIE, A.C. Review of The Appreciation of Ancient and Medieval Science during the Renaissance (1450-4600) e Six Wings. Men Of Science in the Renaissance. The British Journal for the Philosophy of Science, vol.10, $\mathrm{n}^{0}$ 38, p. 164-165, ago.1959.

DUHEM, P. M. M. Études sur Léonard de Vinci: ceux qu'il a lus et ceux qui l'ont lu. Paris: Archives Contemporaines, $3 \mathrm{v}, 1984$.

FEBVRE, L. et al. Léonard de Vinci \& l'expérience scientifique au seizième siècle. Paris: Presses Universitaires de France, 1953.

GRANT, E. Physical Science in the Middle Ages. Cambridge: Cambridge University Press, 1987.

HOYNINGEN-HUENE, P. Reconstructing Scientific Revolution: Thomas S. Kuhn's Philosophy of Science. Chicago: The University of Chicago Press, 1993.

KOYRÉ, A. Études Galiléennes. Paris: Hermann, 1966.

KOYRÉ, A. Galilée et Platon. In KOYRÉ, A. Études d'histoire de la pensée scientifique. Paris: Gallimard, 1973.

KUHN, T. S. Newton's “31 ${ }^{\text {st }}$ Query” and the Degradation of Gold. Isis 42: 296-298, 1951.

KUHN, T. S. Robert Boyle and Structural Chemistry in the Seventeenth Century. Isis 43: 12-36, $1952 \mathrm{a}$.

KUHN, T. S. Reply to M. Boas: Newton and the Theory of Chemical Solutions. Isis 43: 123$124,1952 b$.

KUHN, T. S. The Independence of Density and Pore-size Newton's Theory of Matter. Isis 43: 364-365, $1952 \mathrm{c}$.

KUHN, T. S. The Copernican Revolution. Chicago: UCP, $1970 a$.

KUHN, T. S. The Structure of Scientific Revolutions. Chicago: University of Chicago Press, $1970 b$. 
854 | Veritas | Porto Alegre, v. 63, n. 3, set.-dez. 2018, p. 822-855

KUHN, T. S. The Essential Tension. Chicago: UCP, 1977.

KUHN, T. S. The Road Since Structure. Chicago: University of Chicago, 2000.

LOMBARDI, O. I. La pertinencia de la historia em la enseñanza de ciencias: argumentos y contraargumentos. Enzeñanza de las ciencias, 15 (3), p. 343-349, 1997.

MARCUM, J. A. Thomas Kuhn's Revolution. An Historical Philosophy of Science. London: Continuum, 2005.

MAYORAL, J.V. Las conferencias Lowell de Kuhn: Un estudio crítico. Theoria, 78, p. 459476, 2013.

PACHECO. P. A. James B. Conant y Thomas S. Kuhn. Líneas de continuidad en el estudio histórico de la ciência. Metatheoria 2(1), p. 3-21, 2011.

OLIVEIRA, A. J. Duhem e Kuhn: continuísmo e descontinuísmo na história da ciência. Tese de Doutorado, Instituto de Filosofia e Ciências Humanas, Universidade Estadual de Campinas, Campinas, 2012.

OLIVEIRA, A. J. Kuhn e o conceito de revolução. In: Comte, J.; Mortari, C. A. (orgs). Temas em filosofia contemporânea. Coleção Rumos da Epistemologia 13. Florianópolis: NEL/UFSC, 2014.

OLIVEIRA, A. J. Evolução e mudança conceitual na história da química. Acta Scientiarum. Human and Social Sciences, 37(2), p. 197-208, 2015.

OLIVEIRA, A. J. A obra científica de Leonardo da Vinci: Controvérsias na historiografia da ciência. Trans/Form/Ação, 39 (2) p. 53-86, 2016.

PINTO DE OLIVEIRA, J.C. Kuhn and the genesis of the "new historiography of science". Studies in History and Philosophy of Science. 43, p. 115-121, 2012.

PINTO DE OLIVEIRA, J.C; OLIVEIRA, Amelia. J. Kuhn, Sarton and the History of Science. In: PISANO, R; AGASSI, J; DROZDOVA, D. (eds). Hypotheses and Perspectives in the History and Philosophy of Science. Homage to Alexandre Koyré 1892-1964. Switzerland: Springer, 2018.

PRESTON, J. Kuhn's The Structure of Scientific Revolutions: A Reader's Guide. London: Continuum, 2008.

RUPERT HALL, A. Can the History of Science be History? The Bristish Journal for the History of science, Vol. 4, $\mathrm{N}^{\mathrm{O}}$ 3, p. 207-220, 1969.

SARTON, G. Une encyclopédie léonardesque. Raccolta Vinciana. 10, p. 235-242, 1919.

SARTON, S. "Introduction to the History and Philosophy of Science (Preliminary Note)". Isis, v. 4, $\mathrm{n}^{\mathrm{o}}$ 1, p. 23-31, 1921.

SARTON, G. Introduction to the History of Science. Baltimore: Williams and Wilkins, v. I, 1927. 
A. J. Oliveira - O que é, afinal, conhecimento cumulativo? | 855

SARTON, G. Preface. In: McMURRICH, J. P. Leonardo da Vinci, the Anatomist (1452-1519). Baltimore: The Williams \& Wilkins Company, 1930.

SARTON, G. The Life of Science. New York: Henry Schuman, 1948.

SARTON, G. Boyle and Bayle, the Sceptical Chemist and the Sceptical Historian. Chymia, Vol. 3, p. 155-189, 1950.

SARTON, G. Léonard de Vinci, ingenieur et savant. In: FEVRE et al., 1953.

SARTON, G. The Study of the History of Science. New York: Dover Publications, Inc, 1957.

SARTON, G. A History of Science: Ancient Science through the Golden Age of Greece. Cambridge: Harvard University Press, 1959a.

SARTON, G. A History of Science: Hellenistic Science and Culture in the Last Three Centuries B.C. Cambridge-MA: Harvard University Press, 1959b.

SARTON, G. Science in Renaissance. In: The civilization in the Renaissance, ed. by James W. Thompson et al., 75-95. New York: Frederick Ungar Publishing Co, 1959c.

SARTON, G. On the History of Science: Essays. Selected and edited by Dorothy Stimson. Cambridge: Harvard University Press, 1962a.

SARTON, G. The Quest for Truth: Scientific Progress during the Renaissance. In: FERGUSON, W. et al. The Renaissance. Six Essays. New York: Harper Torchbooks, $1962 b$.

SARTON, G. Introduction to the History of Science. Baltimore: Williams and Wilkins, v. III 1975 .

SARTON, G. The History of science and the New Humanism. New Jersey: Transaction Publishers, 1988.

STIMSON, D. Preface. In: SARTON, 1962.

SWERDLOW, N. M. An Essay on Thomas Kuhn's First Scientific revolution, "The Copernican Revolution”. Proceedings of the American Philosophical Society. 148, 1, p. 64-120, 2004 .

WESTMAN, R.S. Two Cultures or One? A Second Look at Kuhn's The Copernican Revolution. Isis, p. 85: 79-115, 1994. 